\title{
Distant Metastasis
}

National Cancer Institute

\section{Source}

National Cancer Institute. Distant Metastasis. NCI Thesaurus. Code C18206.

A biological process that involves the transfer and growth of cancer cells from the site of the primary tumor. Relocation of malignant cells during metastasis can be restricted to movement within a specific tissue/organ or may entail migration to a distal locus within the body. This phenotype is a characteristic of all malignant tumors. 